\title{
Adaptations to strength training differ between endurance-trained and untrained women
}

\author{
Olav Vikmoen ${ }^{1,2}$ (I) $\cdot$ Truls Raastad $^{2} \cdot$ Stian Ellefsen $^{1,3} \cdot$ Bent R. Rønnestad $^{1}$
}

Received: 31 October 2019 / Accepted: 23 April 2020 / Published online: 5 May 2020

(c) The Author(s) 2020

\begin{abstract}
Purpose The purpose of this study was to investigate if endurance athletes, sustaining their normal endurance training, experience attenuated adaptations to strength training compared to untrained individuals.

Methods Eleven non-strength-trained female endurance athletes $(E+S)$ added 11 weeks of strength training to their normal endurance training $(5.1 \pm 1.1 \mathrm{~h}$ per week), and 10 untrained women $(S)$ performed the same strength training without any endurance training. The strength training consisted of four leg exercises [3×4-10 repetition maximum (RM)], performed twice a week for 11 weeks.

Results $E+S$ and $S$ displayed similar increases in 1RM one-legged leg press $(E+S 39 \pm 19 \%, S 42 \pm 17 \%, p<0.05)$, maximal isometric torque in knee extension $(E+S 12 \pm 11 \%, S 8 \pm 10 \%, p<0.05)$ and lean mass in the legs $(E+S 3 \pm 4 \%, S 3 \pm 3 \%$, $p<0.05)$. However, $S$ displayed superior increases in peak torque in knee extension at an angular velocity of $240^{\circ} \mathrm{sec}^{-1}$ $(E+S 8 \pm 5 \%, S 15 \pm 7 \%, p<0.05)$ and maximal squat jump height $(E+S 8 \pm 6 \%, S 14 \pm 7 \%, p<0.05)$.

Conclusions In this study, concurrent training did not impair the adaptations in the ability to develop force at low contraction velocities or muscle hypertrophy. However, concurrent training attenuated strength training-associated changes in the ability to develop force at higher muscular contraction velocities.
\end{abstract}

Keywords Concurrent training $\cdot$ Muscle strength $\cdot$ Squat jump $\cdot$ Counter movement jump $\cdot$ Muscle hypertrophy

$\begin{array}{ll}\text { Abbreviations } \\ \text { 1RM } & \text { One repetition maximum } \\ \text { CMJ } & \text { Counter movement jump } \\ \text { DXA } & \text { Dual-energy X-ray absorptiometry } \\ \text { ES } & \text { Effect size } \\ \text { E }+ \text { S } & \text { Endurance plus strength training group } \\ \text { Leg }_{\text {LM }} & \text { Lean mass in the legs } \\ \text { MVC } & \text { Maximal isometric torque } \\ \text { RFD } & \text { Rate of force development } \\ \text { S } & \text { Strength training only group }\end{array}$

Communicated by Peter Krustrup.

Olav Vikmoen

olav.vikmoen@nih.no

1 Section for Health and Exercise Physiology, Institute of Public Health and Sport Sciences, Inland Norway University of Applied Sciences, Elverum, Norway

2 Department of Physical Performance, Norwegian School of Sport Sciences, Ullevål Stadion, P.O.box 4014, 0806 Oslo, Norway

3 Innlandet Hospital Trust, Lillehammer, Norway
SD Standard deviation

SJ $\quad$ Squat jump

\section{Introduction}

Since the pioneering study by Hickson (1980), showing that performing strength and endurance training in the same training program (concurrent training) can attenuate increases in maximal strength compared to strength training alone, a large numbers of studies have assessed the effects of concurrent training. Many of these studies have confirmed that concurrent training can lead to impaired strength gains (Bell et al. 2000; Cadore et al. 2010; Gergley 2009; Hunter et al. 1987; Izquierdo et al. 2005; Jones et al. 2013), impaired muscle hypertrophy (Bell et al. 2000; de Souza et al. 2007; Gergley 2009; Putman et al. 2004) and reduced neural adaptations (Cadore et al. 2010; Hakkinen et al. 2003) compared to strength training alone. However, there are also studies that report no negative effects of concurrent training on strength- and hypertrophy-related adaptations (Abernethy and Quigley 1993; Cantrell et al. 2014; 
Gravelle 2000; Holviala et al. 2012; McCarthy et al. 1995; McCarthy et al. 2002; Nelson et al. 1990; Shaw et al. 2009). These conflicting data can probably be ascribed differences in the methodological approaches related to aspects such as training status of the participants, training modality, frequency and volume of strength and endurance training, the manner of integration of the two types of training and the selection of dependent variables.

Interestingly, it has been reported that concurrent training attenuates improvements in peak force at high contraction velocities (Dudley and Djamil 1985), jumping performance (Glowacki et al. 2004; Hunter et al. 1987) and maximal rate of force development (RFD) (Hakkinen et al. 2003) compared to strength training only, despite similar increases in isometric force or one repetition maximum (1RM). This indicates that improvements in the ability to produce force and power at high contraction velocities are more attenuated by concurrent training than changes in the ability to produce high forces during slow shortening velocities. On the contrary, endurance performance seems to be improved in endurance athletes that add heavy strength training to their normal endurance training (e.g. Aagaard et al. 2011; Ronnestad et al. 2015; Sedano et al. 2013), and anecdotally the use of strength training among endurance athletes is increasing. However, the typical studies investigating the concurrent training effect include three groups of similarly trained individuals; one group performing strength training only, one group performing endurance training only and one group performing both the strength training and the endurance training. This leaves the concurrent group with a substantially higher increase in total training volume, prompting it for surplus changes in performance. A possible solution to this issue would be to add strength training to the already ongoing endurance training protocol of endurance athletes, generally finding themselves at a steady-state training and performance level, and to compare its effects with those of adding strength training to previously untrained individuals. This set-up ensures similar changes in training volume in the two groups.

To the best of our knowledge, only two studies have investigated the effects of concurrent training using such a design (Hunter et al. 1987; Ronnestad et al. 2012), though with conflicting conclusions. Whereas Hunter et al. (1987) reported similar increases in 1RM squat and counter movement jump (CMJ) in runners and previously untrained individuals after performing strength training, Ronnestad et al. (2012) reported attenuated gains in 1RM leg strength, thigh muscle CSA, maximal RFD and squat jump (SJ) height in highly trained male cyclists. This discrepancy may be due to the difference in the volume of endurance training. Hunter et al. (1987) assessed recreational active runners performing 1-3 h endurance training per week, whereas Ronnestad et al. (2012) assessed competitive cyclists performing about $10 \mathrm{~h}$ of endurance training per week. Consequently, there is need for studies that elaborate on the effects of concurrent endurance and strength training and its effect on strength-related variables using this design. Furthermore, this design has not previously been used to investigate the effects of concurrent training in female endurance athletes.

The purpose of this study was to compare the effects of 11 weeks of strength training on changes in lean mass in the legs $\left(\operatorname{leg}_{\mathrm{LM}}\right), 1 \mathrm{RM}$, isometric torque, maximal torque at high contraction velocities, and jumping performance between well-trained female endurance athletes with no strength training experience that sustains their normal endurance training and previously untrained age-matched women.

\section{Methods}

\section{Ethical approval}

The study was approved by the Local Ethics Committee at Inland Norway University of Applied Sciences. Written informed consent was obtained from all participants prior to inclusion, and the study was carried out in accordance with the Declaration of Helsinki.

\section{Participants}

Fourteen well-trained female endurance athletes that was active in both cycling and running, [classified according to Jeukendrup et al. (2000)], and 10 untrained female participants were recruited to this study. None of the participants had performed systematic strength training for the 12 months leading up to the study. During the study, three of the endurance athletes left the project for reasons unrelated to the project protocol: one because of an injury not related to the strength training, one because of a prolonged period off illness during the last part of the intervention and one because of other medical reasons.

\section{Experimental overview}

The study was part of a larger study, investigating the effects heavy strength training on various aspects of cycling and running performance. Some of the results on endurance performance have been previously reported (Vikmoen et al. 2016a, b, 2017).

The endurance athletes added heavy strength training to their normal endurance training for 11 weeks $(E+S, n=11)$. The endurance training mainly consisted of cycling and running at an average of $5.1 \pm 1.1 \mathrm{~h}$ per week [for details see Vikmoen et al. (2016a)]. The untrained participants performed the same strength training program, while habitually performing at most one endurance training session per week 
in addition to the strength training $(S, n=10)$. The characteristics of the participants are shown in Table 1.

The strength training program consisted of two sessions per week and lasted for 11 weeks. Physical tests were conducted before and after the intervention period, and were done over three test days, with similar set-ups before and after the intervention. At the first test-day, $\operatorname{leg}_{\mathrm{LM}}$ was determined using dual-energy X-ray absorptiometry (DXA). At the second test day, maximal muscle strength was assessed as one-legged 1RM leg press. At the third test day, maximal jump height in CMJ and SJ was measured followed by a maximal isometric torque (MVC) and an isokinetic peak torque test at $240^{\circ} \cdot \mathrm{sec}^{-1}$ in knee extension. For each participant, all tests were performed at the same time of day before and after the intervention $( \pm 1 \mathrm{~h})$. Prior to physical tests at pre-intervention, participants were given a supervised familiarization session. In this session, proper lifting technique and execution were practiced in all test, and individual equipment settings were found.

\section{Training}

Strength training was performed as described in Vikmoen et al (2016a). Briefly, each training session consisted of half squat in a smith machine, leg press with one leg at a time, standing one-legged hip flexion, and ankle plantar flexion. An investigator supervised all workouts during the first 2 weeks, and at least one workout per week thereafter. During the first 3 weeks, participants trained with 10RM sets at the first session and 6RM sets at the second session of the week. These alternating loads were adjusted to $8 \mathrm{RM}$ and $5 R M$ in weeks $4-6$, and were further adjusted to 6RM and $4 \mathrm{RM}$ in weeks 7-11. The number of sets in each exercise was always three. During warm-up to every training session, participants ingested a protein bar containing $15 \mathrm{~g}$ of protein and $22 \mathrm{~g}$ of carbohydrate (Squeezy recovery bar, Squeezy Sports Nutrition, Braunschweig, Germany). Adherence to the strength training was high, with $E+S$ athletes completing $21.4 \pm 1.0$ (range 19-22) and $S$ participants completing $21.0 \pm 0.8$ (range $20-22$ ) of the planned 22 strength training sessions.

\section{Testing}

\section{Lean mass in the legs}

Leg $_{\mathrm{LM}}$ was determined using DXA using Lunar Prodigy densiometer (Prodigy Advance PA + 302047, Lunar, San Fransisco, CA, USA). Participants were instructed to refrain from training for the $24 \mathrm{~h}$ leading up to the measurement and to refrain from ingesting food or liquid for the $2 \mathrm{~h}$ preceding the measurement. Data from two participants in $S$ were excluded from the data set due to technical problems with analyses. Therefore, the numbers of participants included in the $\operatorname{leg}_{\mathrm{LM}}$ data are 11 in $E+S$ and 8 in $S$.

\section{$1 \mathrm{RM}$ in one-legged leg press}

Following 10 min warm-up on a cycle ergometer, the 1RM test started with a specific warm-up, consisting of three sets with gradually increasing load (40, 75 and $85 \%$ of expected $1 \mathrm{RM})$ and decreasing number of repetitions $(10 \rightarrow 6 \rightarrow 3)$. The first attempt was performed with a load approximately $5 \%$ below the expected $1 \mathrm{RM}$. The expected $1 \mathrm{RM}$ was deduced from data obtained during the familiarization session. If a lift was successful, the load was increased by approximately $5 \%$. The test was terminated when the participants failed to lift the load in 2-3 attempts. The highest successful load lifted was defined as 1RM. Participants were given 3 min of rest between lifts.

\section{SJ and CMJ}

After 10-min warm-up on a cycle ergometer, SJ and CMJ jumps were performed on a force plate (SG-9, Advanced Mechanical Technologies, Newton, MA, USA, sampling frequency of $1 \mathrm{kHz}$ ). After 3-5 submaximal warm-up jumps, the participants performed three SJ and three CMJ with 2-3 min rest between each jump. The mean of the two highest SJ and CMJ were utilized for statistical analyses. During all jumps, the participants were instructed to keep their hands placed on their hips and to aim for maximal jumping height. The $\mathrm{SJ}$ was performed from approximately 90 degrees knee angle. In this position, they paused for $3 \mathrm{~s}$

Table 1 Characteristics of the athletes adding strength training to their normal endurance training $(E+S)$ and the untrained individuals performing strength training only $(S)$

\begin{tabular}{lllllll}
\hline Group & $\mathrm{N}$ & Age (years) & Height $(\mathrm{m})$ & Body mass $(\mathrm{kg})$ & $\mathrm{BMI}\left(\mathrm{kg} / \mathrm{m}^{2}\right)$ & $\begin{array}{l}V \mathrm{O}_{2 \mathrm{max}} \\
\left(\mathrm{ml} \mathrm{kg}^{-1} \mathrm{~min}^{-1}\right)\end{array}$ \\
\hline$E+S$ & 11 & $31.5 \pm 8.0$ & $1.69 \pm 0.05$ & $62.2 \pm 5.2$ & $21.7 \pm 1.3$ & $54 \pm 3$ \\
$S$ & 10 & $31.0 \pm 9.9$ & $1.72 \pm 0.04$ & $67.8 \pm 13.5$ & $22.8 \pm 3.9$ & NA \\
\hline
\end{tabular}

Values are mean \pm SD

$V O_{2 \max }$ maximal oxygen consumption 
before the jump was performed. No downward movement was allowed prior to the jump and the force curves were inspected to verify this. During the eccentric phase of the CMJ, the participants were instructed to turn at a knee angle they felt was optimal for achieving maximal jump height. Vertical jumping height was calculated from the impulse from the ground reaction force.

\section{Maximal isometric torque and isokinetic torque at an angular velocity of $240^{\circ} \cdot \mathrm{sec}^{-1}$}

After the jump tests, peak torque during MVC and isokinetic knee extension were measured in a dynamometer (Cybex 6000, Cybex International, Medway, USA). During these tests, the participants were seated with a $90^{\circ}$ hip angle and were stabilized in this position using chest, hip and thigh straps. The input axis of the dynamometer was aligned with the participants' knee joint and the ankle was strapped to a lever arm. The participants held their arms in front of their chest during all tests. First, the participants performed three maximal knee extensions against the lever arm at a $90^{\circ}$ knee angle. Contractions lasted for $5 \mathrm{~s}$, with 1 min rest between attempts. The participants were instructed to perform the muscle action as forcefully and quickly as possible. The attempt with the highest maximal torque was chosen for statistical analyses. Two minutes after the last MVC, three maximal isotonic knee extensions were performed from $90^{\circ}$ knee angle to full extension against the lever arm at an angular velocity of $240^{\circ} \cdot \mathrm{sec}^{-1}$, with one minute rest between attempts. The attempt with the highest torque was chosen for statistical analyses. Strong verbal encouragement was given to participants during all attempts but without live visual feedback of the torque curves.

\section{Dietary intake}

In the sixth training week, participants recorded their daily dietary intake for four days using the weighed-food-intake method. These 4 days included 3 weekdays (not Friday) and either Saturday or Sunday. The participants weighed all their consumed food using digital food weights (Wilfa KW-4, Wilfa AS, Hagan, Norway) and tracked their intake in written journals. All participants were given detailed written and verbal guidelines about how to carry out this method. Dietary data were analyzed using a nutrient analysis software (Kostholdsplanleggeren 2014, Norwegian Food Safety Authority and The Norwegian Directorate of Health, Oslo, Norway).

\section{Statistics}

All data in the text, figures and tables are presented as mean \pm standard deviation, unless otherwise stated.
Unpaired Student's $t$ test were utilized to test for differences between groups at pre and post, and to test for differences in changes from pre to post between groups. Paired $t$ tests were utilized to test for within-group analyses. Effect sizes (ES) were calculated for key performance and physiological adaptations between groups to elucidate on the practical significance of strength training. ES were calculated as Cohen's $d$ and the criteria to interpret the magnitude were the following: $0-0.2=$ trivial, $0.2-0.6=$ small, $0.6-1.2=$ moderate, $1.2-2.0=$ large and ${ }^{\prime} 2=$ very large (Hopkins et al. 2009).

\section{Results}

\section{Lean mass in the legs, training load and maximal strength}

Body mass remained unchanged in $E+S$ (from $62.4 \pm 5.2$ to $63.1 \pm 5.6 \mathrm{~kg}$ ) and in $S$ (from $67.8 \pm 13.5$ to $68.0 \pm 12.3 \mathrm{~kg}$ ). In $E+S$ and $S, 11$ weeks of strength training led to similar increases in $\operatorname{Leg}_{\mathrm{LM}}\left(E+S 3.1 \pm 4.0 \%, S 3.3 \pm 3.3 \%, p^{<} 0.05\right.$; Fig. 1), 1RM one-legged leg press $\left(E+S 39 \pm 19 \%, p^{<} 0.05\right.$, $S 42 \pm 17 \%, p^{<} 0.05$; Fig. 1), maximal isometric torque $(E+S$ $12 \pm 11 \%, S 8 \pm 10 \%, p^{<} 0.05$; Fig. 1$)$, and progression in $6 \mathrm{RM}$ load $(\mathrm{kg})$ from week 2 to week $11(E+S 39 \pm 11 \%, S$ $40 \pm 11 \%, p^{<} 0.05$; Fig. 2).

\section{SJ and CMJ}

Before the intervention period, $E+S$ performed better than $S$ (Fig. 3) in both SJ $(E+S 24.3 \pm 6.0 \mathrm{~cm}, S 18.9 \pm 3.2 \mathrm{~cm}$, $\left.p^{<} 0.05\right)$ and $\mathrm{CMJ}(E+S 25.6 \pm 4.2 \mathrm{~cm}, S 21.0 \pm 3.6 \mathrm{~cm}$, $\left.p^{<} 0.05\right)$.

The intervention led to improved SJ $(E+S 8 \pm 6 \%, \mathrm{~S}$ $\left.14 \pm 7 \%, p^{<} 0.05\right)$ and $\mathrm{CMJ}\left(E+S 6 \pm 6 \%, S 11 \pm 8 \%, p^{<} 0.05\right)$ in both groups (Fig. 3). The increase in SJ was larger in $S$ than in $E+S\left(p^{<0.05)}\right.$ while there was no statistically difference in the increase in CMJ $(p=0.11)$. The effect size analyses revealed a moderate practical effect in favor of the $S$ group for both SJ $(\mathrm{ES}=0.95)$ and $\mathrm{CMJ}(\mathrm{ES}=0.73)$. Peak torque at $240^{\circ} \cdot \mathrm{sec}^{-1}$ was improved in both groups $(E+S$ $8 \pm 5 \%, S 15 \pm 7 \%, p^{<} 0.05$, Fig. 3). The improvement in $S$ was significantly larger than in $E+S\left(p^{<} 0.05\right.$, Fig. 3), with a moderate practical effect $(\mathrm{ES}=1.11)$.

\section{Dietary intake}

There was no difference in total energy intake or carbohydrate and fat intake between $E+S$ and $S$, neither in absolute values nor in values normalized to body mass (Table 2 ). However, $E+S$ had higher protein intake than $S$, both in 

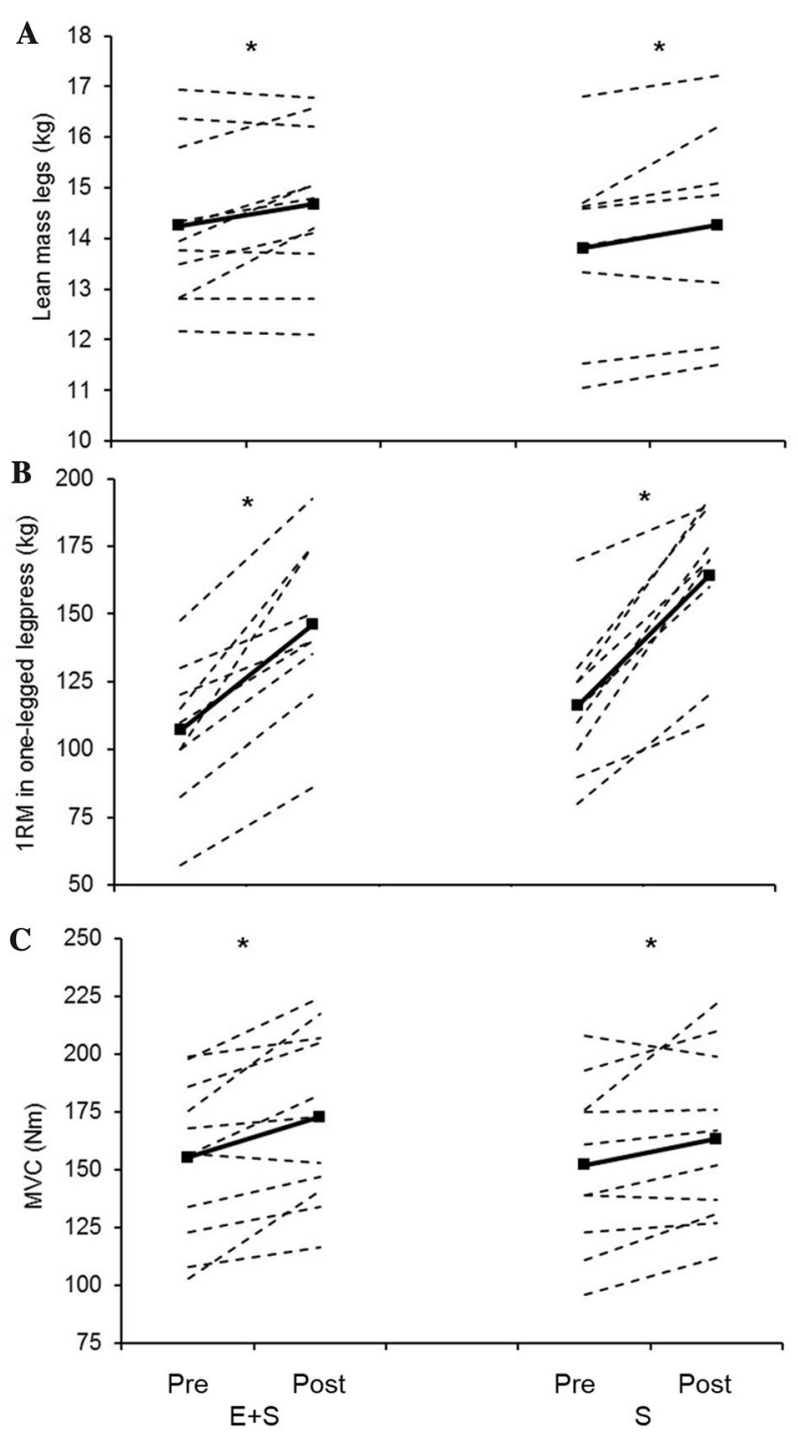

Fig. 1 Individual values (dotted lines) and mean values (solid lines) before (pre) and after (post) the intervention period for athletes adding strength training to their normal endurance training $(E+S)$, and previously untrained individuals performing strength training only $(S)$. a Lean mass in the legs. b 1 repetition maximum (1RM) in one-legged leg press. c Maximal isometric torque in knee extension (MVC). *Larger than pre $(p<0.05)$

absolute values $\left(p^{<} 0.05\right.$, Table 2$)$ and as values normalized to body mass ( $p^{<} 0.05$, Table 2$)$.

\section{Discussion}

In the current study, 11 weeks of strength training led to similar improvements in leg muscle mass and development of force at low contraction velocities in endurance athletes maintaining their normal endurance training and untrained individuals. Interestingly, the ability to develop muscular

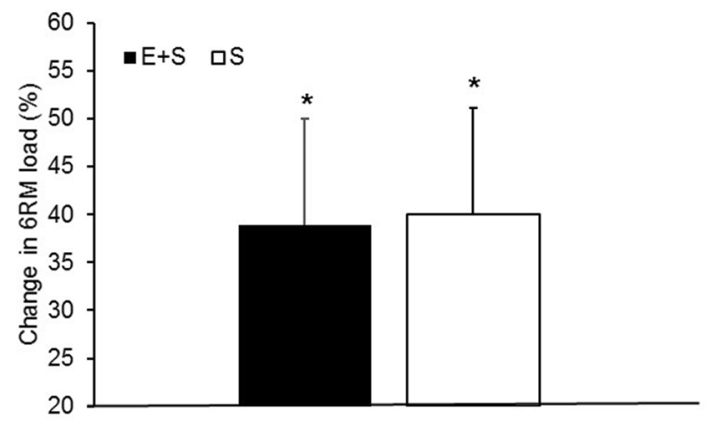

Fig. 2 Percent change in 6 repetition maximum (6RM) load from training week 2 to training week 11 during the intervention period for athletes adding strength training to their normal endurance training $(E+S)$, and previously untrained participants performing strength training only $(S)$. *Significant increase from pre $(p<0.01)$

power increased more in the untrained participants as shown by the greater improvement in jumping performance and maximal isokinetic torque at high contraction velocities.

\section{The ability to develop force at low contraction velocities and $\operatorname{leg}_{\mathrm{LM}}$}

In the present study, concurrent training did not impair adaptation in the ability to develop force at low contraction velocities and muscle hypertrophy, as evident from similar increases in 1RM, MVC and $\operatorname{leg}_{\mathrm{LM}}$ between $E+S$ and $S$. This contradicts the interference effect, a phenomenon that was first reported by Hickson (1980), where concurrent training led to smaller increases in 1RM squat during the last 3 weeks of a 10-week training period compared to a group performing strength training only. The interference effect has since been supported by several studies demonstrating attenuated changes in maximal strength (Bell et al. 2000; Cadore et al. 2010; Gergley 2009; Hickson 1980; Hunter et al. 1987; Izquierdo et al. 2005; Jones et al. 2013; Kraemer et al. 1995) and muscle hypertrophy (Bell et al. 2000; Karavirta et al. 2011; Kraemer et al. 1995; Putman et al. 2004; Ronnestad et al. 2012). However, there are also numerous studies reporting no negative effect of concurrent endurance training on changes in maximal strength at low contraction velocities and muscle hypertrophy after a strength training intervention (Abernethy and Quigley 1993; Cantrell et al. 2014; Holviala et al. 2012; McCarthy et al. 1995, 2002; Nelson et al. 1990; Shaw et al. 2009). The reasons for these conflicting results are unclear, but they are probably due to methodical differences between studies, for example in training status of study participants and total training volume.

Studies that report impaired increases in maximal strength and muscle hypertrophy in response to concurrent training tend to include higher numbers of total training sessions (six or more) and endurance training sessions per week (Bell 


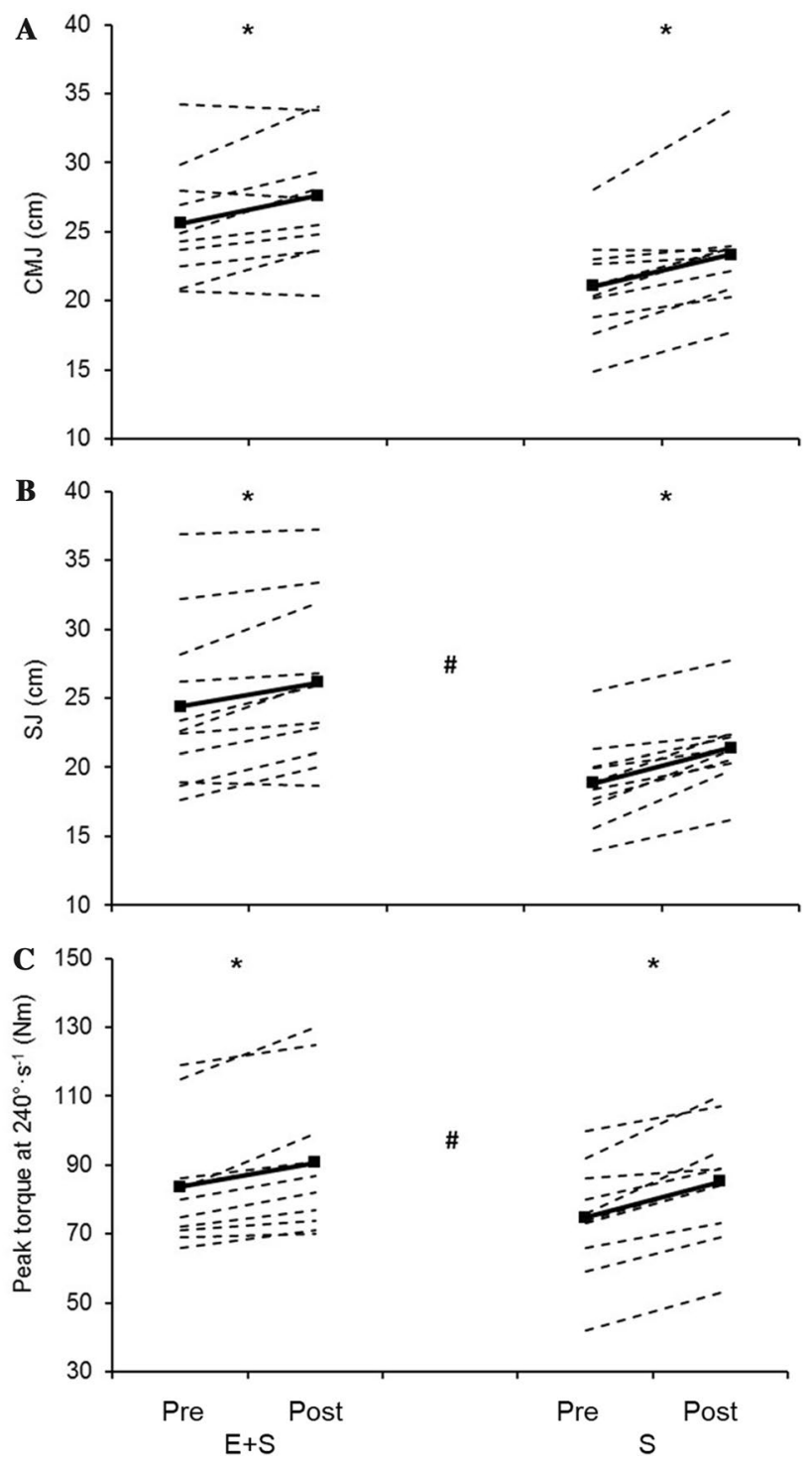

Fig. 3 Individual values (dotted lines) and mean values (solid lines) before (Pre) and after (Post) the intervention period for athletes adding strength training to their normal endurance training $(E+S)$, and previously untrained individuals performing strength training only (S). a Counter movement jump (CMJ). b Squat jump (SJ). c Peak torque in isokinetic knee extension at an angular velocity of $240^{\circ} \cdot \mathrm{s}^{-1}$. *Larger than pre $(p<0.05)$, \# the percent change from pre is different between $E+S$ and $E(p<0.05)$

et al. 2000; Hickson 1980; Hunter et al. 1987; Jones et al. 2013; Kraemer et al. 1995) than studies that do not report attenuated adaptations (Holviala et al. 2012; McCarthy et al. 1995, 2002; Shaw et al. 2009), even though exceptions exist (de Souza et al. 2007; Gergley 2009; Izquierdo et al. 2005). Therefore, the total amount of concurrent training performed is probably an important factor for impairments in strength training adaptations to occur. In accordance with this, Jones et al. (2013) reported attenuated strength adaptations in recreationally strength-trained men after concurrent training
Table 2 Energy and macro-nutrient intake for athletes adding strength training to their normal endurance training $(E+S)$ and previously untrained individuals performing strength training only $(S)$

\begin{tabular}{lcc}
\hline Nutrient & $E+S$ & $S$ \\
\hline Energy intake $\left(\mathrm{kJ} \mathrm{day}^{-1}\right)$ & $8901 \pm 2119$ & $7752 \pm 811$ \\
Energy intake $\left(\mathrm{kJ} \mathrm{kg}^{-1} \mathrm{day}^{-1}\right)$ & $141 \pm 24$ & $123 \pm 32$ \\
Carbohydrate $\left(\mathrm{g} \mathrm{day}^{-1}\right)$ & $218 \pm 93$ & $232 \pm 35$ \\
Carbohydrate $\left(\mathrm{g} \mathrm{kg}^{-1} \mathrm{day}^{-1}\right)$ & $3.5 \pm 1.5$ & $3.6 \pm 0.9$ \\
Protein $\left(\mathrm{g} \mathrm{day}^{-1}\right)$ & $104 \pm 26^{*}$ & $67 \pm 26$ \\
Protein $\left(\mathrm{g} \mathrm{kg}^{-1} \mathrm{day}^{-1}\right)$ & $1.7 \pm 0.4^{*}$ & $1.2 \pm 0.3$ \\
Fat $\left(\mathrm{g} \mathrm{day}^{-1}\right)$ & $80 \pm 26$ & $75 \pm 11$ \\
Fat $\left(\mathrm{g} \mathrm{kg}^{-1} \mathrm{day}^{-1}\right)$ & $1.3 \pm 0.3$ & $1.2 \pm 0.3$ \\
\hline
\end{tabular}

Values are mean $\pm \mathrm{SD}$

*Larger than $S(p<0.05)$

with three endurance training session per week but not with one session.

The present study investigated whether well-trained female endurance athletes, maintaining a steady level of endurance training, show different adaptations to strength training than previously untrained individuals. With this design, the actual increase in training volume from adding strength training was similar between intervention groups. Our results conflict with data from a previous study using a similar design (Ronnestad et al. 2012), where increases in 1RM and muscle CSA were attenuated in well-trained male cyclists performing 12 weeks of heavy strength training compared to recreational active individuals performing strength training only. This discrepancy may be due to the amount of endurance training performed. In the current study, $E+S$ performed about $5 \mathrm{~h}$ of endurance training per week, as compared to about $10 \mathrm{~h}$ per week in the study by Ronnestad et al. (2012). Supporting this, in recreationally active runners, $1-3 \mathrm{~h}$ of endurance training did not impair strength training adaptations (Hunter et al. 1987). Although the large differences in endurance training volume seems like a plausible explanation for why we, in contrast to Ronnestad et al. (2012), did not find attenuated muscle hypertrophy with concurrent training, we cannot exclude possible sex differences.

The higher protein intake in $E+S$ compared to $S$ poses a challenge for interpretation of the changes in $\operatorname{leg}_{\mathrm{LM}}$ in the two groups. Nutritional status, especially energy balance and protein intake, impacts muscular adaptations to strength training (Garthe et al. 2013; Rodriguez et al. 2009), with protein intake alone also stimulating myofibrillar protein synthesis (Phillips et al. 2005). A recent meta-analysis concluded that protein supplementation up to a daily intake of $1.62 \mathrm{~g} / \mathrm{kg}$ augments strength training-induced gains in muscle mass (Morton et al. 2018). The $S$ group in the current study was below this limit. However, both groups had 
protein intakes that were within ACSM's recommendations for endurance- and strength-trained athletes (Rodriguez et al. 2009). Moreover, the overall energy intake was similar between groups, despite $E+S$ performing $5 \mathrm{~h}$ of endurance training per week indicating that the total energy balance was more positive in $S$ than in $E+S$. Therefore, it is difficult to assess the effects of the different protein intake between the groups, but we cannot exclude the possibility that the larger protein intake in $E+S$ may have mitigated a possible negative effect of endurance training on the increase in $\operatorname{leg}_{\mathrm{LM}}$.

\section{The ability to develop forces at high contraction velocities and jumping ability}

In $E+S$, strength training-associated increases in peak torque at high contraction velocities and jumping performance was attenuated. Concurrent training thus impaired power-related adaptations, without affecting increases in force production at low muscle contraction velocities or hypertrophy, largely resembling some previous classic concurrent training studies (Dudley and Djamil 1985; Glowacki et al. 2004; Hakkinen et al. 2003). Attenuated increase in jumping performance after strength training have also been reported in well-trained male cyclists continuing their normal endurance training (Ronnestad et al. 2012).

The underlying mechanisms behind concurrent training negatively affecting power-related adaptations more than maximal strength and hypertrophy remain unclear, and our study design was not suited for elucidating on this perspective. However, the ability to produce power and force at high contraction velocities is in addition to maximal muscular strength, depended on relative proportions of type II muscle fibers (Fitts and Widrick 1996), rapid neural activation of the muscles (Folland and Williams 2007; Rhea et al. 2008) and muscle fascicle length (Blazevich 2006). Concurrent training does not seem to affect strength traininginduced adaptations in type II muscle fibers (Kraemer et al. 1995; Putman et al. 2004), at least not in subjects with similar training status. In addition, studies reporting impaired hypertrophy in muscle fibers after concurrent training indicate that this happens predominately in the type I fibers (Bell et al. 2000; Kraemer et al. 1995). Therefore, the effects of concurrent training on fiber type do probably not explain the impairing effects on power and rapid force production. Hakkinen et al. (2003) reported reduced adaptations in RFD together with a lack of increased iEMG in $m$. vastus lateralis muscle during the first $500 \mathrm{~ms}$ of isometric knee extension after concurrent training compared to strength training only, indicating attenuated development of rapid voluntary neural activation (Hakkinen et al. 2003). It remains unknown if concurrent training affects muscle fascicle length differently than strength training alone. To our best knowledge, no concurrent training study has investigated this aspect and studies investigating the effects of endurance training on muscle architecture yields diverging results (Farup et al. 2012; Murach et al. 2015).

Notably, the superior gains in jump performance in $S$ in the present data could be the result of lower performance levels at baseline compared to $E+S$, perhaps related to better motor skills and non-significant lower body mass. As the two groups performed similarly in all other strength exercises at baseline, they seemed to possess similar abilities to activate slow and fast muscle fibers. Furthermore, the smaller increase seen in in peak torque at high contraction velocities in the less coordinative demanding knee extension exercise, supports that the superior gains in jump performance in $\mathrm{S}$ was because of an interfering effect of concurrent training in $E+S$. It thus seems reasonable to suggest that the difference in improvement in jumping performance between $E+S$ and $S$ was related to the concurrent training protocol.

\section{Conclusion}

In the present study, well-trained female endurance athletes who maintained a steady-state endurance training consisting of about $5 \mathrm{~h}$ per week had similar increases in the ability to develop force at low muscular contractions velocities, and comparable gains in $\operatorname{leg}_{\mathrm{LM}}$ after 11 weeks of heavy strength training as previously untrained females. However, concurrent training attenuated strength trainingassociated changes in development of force at higher muscular contraction velocities. This supports the notion that concurrent training interferes with power-related adaptations to strength training.

Acknowledgements Open Access funding provided by Norwegian School Of Sport Sciences - The Library. The authors would like to thank the participants for their time and effort and students Øyvind Trøen, Roger Kristoffersen, Allan Sørgaard Nielsen, Sondre Prestkvern, Damir Feuce, Erland Thomassen and Karl Petter Fon for assistant during the intervention follow-up and data sampling. This work was supported by Grant 203961 from the Regional Science Fund-Innlandet of Norway.

Author contributions All authors contributed to the study conception, design and preparation. Data collection and analysis were performed by $\mathrm{OV}$. The first draft of the manuscript was written by OV and all authors commented on previous versions of the manuscript. All authors read and approved the final manuscript.

\section{Compliance with ethical standards}

Conflict of interest The authors declare that they have no conflict of interest. 
Open Access This article is licensed under a Creative Commons Attribution 4.0 International License, which permits use, sharing, adaptation, distribution and reproduction in any medium or format, as long as you give appropriate credit to the original author(s) and the source, provide a link to the Creative Commons licence, and indicate if changes were made. The images or other third party material in this article are included in the article's Creative Commons licence, unless indicated otherwise in a credit line to the material. If material is not included in the article's Creative Commons licence and your intended use is not permitted by statutory regulation or exceeds the permitted use, you will need to obtain permission directly from the copyright holder. To view a copy of this licence, visit http://creativecommons.org/licenses/by/4.0/.

\section{References}

Aagaard P et al (2011) Effects of resistance training on endurance capacity and muscle fiber composition in young top-level cyclists. Scand J Med Sci Sports 21:e298-307. https://doi.org/ 10.1111/j.1600-0838.2010.01283.x

Abernethy PJ, Quigley BM (1993) Concurrent strength and endurance training of the elbow extensors. J Strength Cond Res 7(4):234-240

Bell GJ, Syrotuik D, Martin TP, Burnham R, Quinney HA (2000) Effect of concurrent strength and endurance training on skeletal muscle properties and hormone concentrations in humans. Eur J Appl Physiol 81:418-427

Blazevich AJ (2006) Effects of physical training and detraining, immobilisation, growth and aging on human fascicle geometry. Sports Med 36:1003-1017

Cadore EL et al (2010) Physiological effects of concurrent training in elderly men. Int J Sports Med 31:689-697. https://doi. org $/ 10.1055 / \mathrm{s}-0030-1261895$

Cantrell GS, Schilling BK, Paquette MR, Murlasits Z (2014) Maximal strength, power, and aerobic endurance adaptations to concurrent strength and sprint interval training. Eur J Appl Physiol 114:763-771. https://doi.org/10.1007/s00421-013-2811-8

de Souza EO, Tricoli V, Franchini E, Paulo AC, Regazzini M, Ugrinowitsch C (2007) Acute effect of two aerobic exercise modes on maximum strength and strength endurance. J Strength Cond Res 21:1286-1290. https://doi.org/10.1519/R-20686.1

Dudley GA, Djamil R (1985) Incompatibility of endurance- and strength-training modes of exercise. J Appl Physiol 59:1446-1451

Farup J et al (2012) Muscle morphological and strength adaptations to endurance vs. resistance training. J Strength Cond Res 26:398-407. https://doi.org/10.1519/JSC.0b013e318225a26f

Fitts RH, Widrick JJ (1996) Muscle mechanics: adaptations with exercise-training. Exerc Sport Sci Rev 24:427-473

Folland JP, Williams AG (2007) The adaptations to strength training: morphological and neurological contributions to increased strength. Sports Med 37:145-168

Garthe I, Raastad T, Refsnes PE, Sundgot-Borgen J (2013) Effect of nutritional intervention on body composition and performance in elite athletes. Eur J Sport Sci 13:295-303. https:// doi.org/10.1080/17461391.2011.643923

Gergley JC (2009) Comparison of two lower-body modes of endurance training on lower-body strength development while concurrently training. J Strength Cond Res 23:979-987. https://doi. org/10.1519/JSC.0b013e3181a0629d

Glowacki SP, Martin SE, Maurer A, Baek W, Green JS, Crouse SF (2004) Effects of resistance, endurance, and concurrent exercise on training outcomes in men. Med Sci Sports Exerc 36:2119-2127

Gravelle BJ, Blessing DI (2000) Physiological adaptations in women concurrently training for strength and endurance. J Strength Cond Res 14:5-13
Hakkinen K et al (2003) Neuromuscular adaptations during concurrent strength and endurance training versus strength training. Eur J Appl Physiol 89:42-52. https://doi.org/10.1007/s0042 1-002-0751-9

Hickson RC (1980) Interference of strength development by simultaneously training for strength and endurance. Eur J Appl Physiol Occup Physiol 45:255-263

Holviala J et al (2012) Effects of strength, endurance and combined training on muscle strength, walking speed and dynamic balance in aging men. Eur J Appl Physiol 112:1335-1347. https://doi. org/10.1007/s00421-011-2089-7

Hopkins WG, Marshall SW, Batterham AM, Hanin J (2009) Progressive statistics for studies in sports medicine and exercise science. Med Sci Sports Exerc 41:3-13. https://doi.org/10.1249/ MSS.0b013e31818cb278

Hunter G, Demment R, Miller D (1987) Development of strength and maximum oxygen uptake during simultaneous training for strength and endurance. J Sports Med Phys Fitness 27:269-275

Izquierdo M, Hakkinen K, Ibanez J, Kraemer WJ, Gorostiaga EM (2005) Effects of combined resistance and cardiovascular training on strength, power, muscle cross-sectional area, and endurance markers in middle-aged men. Eur J Appl Physiol 94:70-75. https ://doi.org/10.1007/s00421-004-1280-5

Jeukendrup AE, Craig NP, Hawley JA (2000) The bioenergetics of World Class Cycling. J Sci Med Sport 3:414-433

Jones TW, Howatson G, Russell M, French DN (2013) Performance and neuromuscular adaptations following differing ratios of concurrent strength and endurance training. J Strength Cond Res 27:3342-3351. https://doi.org/10.1519/JSC.0b013e3181b2cf39

Karavirta L et al (2011) Effects of combined endurance and strength training on muscle strength, power and hypertrophy in 40-67-year-old men. Scand J Med Sci Sports 21:402-411. https ://doi.org/10.1111/j.1600-0838.2009.01059.x

Kraemer WJ et al (1995) Compatibility of high-intensity strength and endurance training on hormonal and skeletal muscle adaptations. J Appl Physiol 78:976-989

McCarthy JP, Agre JC, Graf BK, Pozniak MA, Vailas AC (1995) Compatibility of adaptive responses with combining strength and endurance training. Med Sci Sports Exerc 27:429-436

McCarthy JP, Pozniak MA, Agre JC (2002) Neuromuscular adaptations to concurrent strength and endurance training. Med Sci Sports Exerc 34:511-519

Morton RW et al (2018) A systematic review, meta-analysis and metaregression of the effect of protein supplementation on resistance training-induced gains in muscle mass and strength in healthy adults. Br J Sports Med 52:376. https://doi.org/10.1136/bjsports2017-097608

Murach K, Greever C, Luden ND (2015) Skeletal muscle architectural adaptations to marathon run training. Appl Physiol Nutr Metab 40:99-102. https://doi.org/10.1139/apnm-2014-0287

Nelson AG, Arnall DA, Loy SF, Silvester LJ, Conlee RK (1990) Consequences of combining strength and endurance training regimens. Phys Ther 70:287-294

Phillips SM, Hartman JW, Wilkinson SB (2005) Dietary protein to support anabolism with resistance exercise in young men. $\mathbf{J}$ Am Coll Nutr 24:134S-139S. https://doi.org/10.1080/07315 724.2005.10719454

Putman CT, Xu X, Gillies E, MacLean IM, Bell GJ (2004) Effects of strength, endurance and combined training on myosin heavy chain content and fibre-type distribution in humans. Eur J Appl Physiol 92:376-384. https://doi.org/10.1007/s00421-004-1104-7

Rhea MR, Oliverson JR, Marshall G, Peterson MD, Kenn JG, Ayllon FN (2008) Noncompatibility of power and endurance training among college baseball players. J Strength Cond Res 22:230-234. https://doi.org/10.1519/JSC.0b013e31815fa038 
Rodriguez NR, DiMarco NM, Langley S (2009) Position of the American Dietetic Association, Dietitians of Canada, and the American College of Sports Medicine: nutrition and athletic performance. J Am Diet Assoc 109:509-527

Ronnestad BR, Hansen EA, Raastad T (2012) High volume of endurance training impairs adaptations to 12 weeks of strength training in well-trained endurance athletes. Eur J Appl Physiol 112:14571466. https://doi.org/10.1007/s00421-011-2112-z

Ronnestad BR, Hansen J, Hollan I, Ellefsen S (2015) Strength training improves performance and pedaling characteristics in elite cyclists. Scand J Med Sci Sports 25:e89-98. https://doi. org/10.1111/sms. 12257

Sedano S, Marin PJ, Cuadrado G, Redondo JC (2013) Concurrent training in elite male runners: the influence of strength versus muscular endurance training on performance outcomes. J Strength Cond Res 27:2433-2443. https://doi.org/10.1519/JSC.0b013e3182 $80 \mathrm{cc} 26$

Shaw BS, Shaw I, Brown GA (2009) Comparison of resistance and concurrent resistance and endurance training regimes in the development of strength. J Strength Cond Res 23:2507-2514. https:// doi.org/10.1519/JSC.0b013e3181bc191e
Vikmoen O, Ellefsen S, Troen O, Hollan I, Hanestadhaugen M, Raastad T, Ronnestad BR (2016a) Strength training improves cycling performance, fractional utilization of VO2max and cycling economy in female cyclists. Scand J Med Sci Sports 26:384-396. https:// doi.org/10.1111/sms. 12468

Vikmoen O, Raastad T, Seynnes O, Bergstrom K, Ellefsen S, Ronnestad BR (2016b) Effects of heavy strength training on running performance and determinants of running performance in female endurance athletes. PLoS ONE 11:e0150799. https://doi. org/10.1371/journal.pone.0150799

Vikmoen O, Ronnestad BR, Ellefsen S, Raastad T (2017) Heavy strength training improves running and cycling performance following prolonged submaximal work in well-trained female athletes. Physiol Rep. https://doi.org/10.14814/phy2.13149

Publisher's Note Springer Nature remains neutral with regard to jurisdictional claims in published maps and institutional affiliations. 